\title{
Causality Analysis of Total Energy Consumption and Export Trade: An Example of Hubei
}

\author{
Chunying Cui \\ Internet and Industrial Innovation Development Research \\ Center \\ Wenhua College \\ Wuhan, China
}

\author{
Zhaoying Lu, Qingmei Li* \\ Department of Economics and Management \\ Wenhua College \\ Wuhan, China
}

\begin{abstract}
An empirical research method for causality verification was proposed by using vector autoregressive VAR model for the interaction between economic energy consumption and local export trade activities. Through time series analysis, the Granger causality test was carried out on the total energy consumption and export trade data of Hubei Province from 1988 to 2017. It was found that the energy consumption of Hubei had a positive causal relationship with the change of export trade volume and passed the pulse. The robustness of the conclusion is tested by the response function and the variance decomposition.
\end{abstract}

Keywords-energy consumption; export trade; vector autoregression; time series analysis

\section{INTRODUCTION}

China has increased national GDP by the rapid expansion of the international trade exports on a global scale. Therefore, the procession exacerbated the sharp consumption of natural resources and environmental pollution. The development of society is inseparable from the use of non-renewable energy. Although China is constantly developing new energy sources, non-renewable renewable energy is still the most important energy source in use, because the use of energy is unreasonable, resulting in a large amount of waste. The ecological environment has been damaged and polluted, which affects the health and life of Chinese people.

The classic study by Aryel Hillman and Clark. W. Bullard (1978) pioneered the research of energy consumption and trade relations[1,2]. T. Owen, Romir and Vinod (1982) studied the impact mechanism of energy and foreign trade from the perspective of net export and net import of energy[3]. They believe that the rapid expansion of Latin American exports is an important cause of energy supply shortage. The study by Jose Goldemberg (1984) also supports this point of view[4].

In the 1990s, researchers concentrate the relationship between trade and the environment. Grossman and Krueger (1991) analyzed the relationship between the degree of deterioration of the North American environment and economic growth, and first conducted an environmental Kuznets curve (EKC) test. It is believed that the environmental quality index of most countries or regions shows the characteristics of the inverted U-shaped curve with the increase of per capita income.
There are three main types of research contributed by Chinese scholars: a) The total energy consumption promotes the growth of export trade and is an important support for the development of export trade[5]; b) Export trade drives energy consumption, while energy consumption is not the reason for export trade [6]; c) Some studies based on the Granger causality test found that the total energy consumption and export trade affect each other and cause each other[7].

It can be seen from the above that the presently study have different opinions on the relationship between energy consumption and the total amount of local foreign trade, many conclusions actually conflict with each other. This paper uses data from Hubei Province and hopes to conduct time series analysis through VAR model to verify causality to further enrich research in foreign trade and energy-related fields.

\section{ANALYSIS OF THE CURRENT SITUATION OF ENERGY CONSUMPTION CHANGES AND EXPORT TRADE VOLUME IN HuBEI PROVINCE}

\section{A. Analysis of the current situation of energy consumption changes in Hubei Province}

Hubei Province is a typical energy importing province, and a large amount of coal and crude oil are transferred to the province every year. Coal in Hubei Province has a higher proportion of primary energy production and consumption, but oil and natural gas account for a lower proportion of primary energy production and consumption. Since the West-East Gas Pipeline Project has penetrated Hubei in 2009, the annual use of natural gas has soared from 679 million cubic meters in 2008 to 2.82 billion cubic meters in 2017, which has quadrupled in 10 years. Correspondingly, the annual consumption of coal will gradually increase until the breakthrough of 80 million tons before 2013. After 2013, the annual consumption of coal will continue to decline, falling back to 70 million tons. In the same period, the consumption of crude oil has increased by $70 \%$ in ten years.

The province's total energy consumption from 1988 to 2017 increased from 38.7 to 171.5 million tons of standard coal, which increased by $443 \%$ in 30 years. The energy input from other provinces has been higher than the province's primary energy production. The amount of energy consumption in the province shows a growth trend, the facts reflect the increasing 
demand for the total energy consumption in the future development of Hubei Province.

According to the previous analysis, energy consumption in Hubei Province is extremely dependent on other provinces. the energy input as a kind of production factors, the output production can bring economic growth. But the inherent problem of insufficient supply of energy in Hubei Province will hinder the sustainable development of the economy.

\section{B. The variation trend of energy consumption ratio of export products and GDP per unit output value in Hubei Provinces}

The energy consumption per unit of output value of export products refers to the amount of energy consumed by the unit's export trade, reflecting the dependence of export trade on energy consumption.

Trade energy consumption ratio $=$ Total energy consumption / Trade volume, in units of tons of standard coal / 10,000 US dollars. / GDP.

GDP energy consumption ratio = Total energy consumption

The energy consumption per unit of output value of trade exports in Hubei Province has always been higher than the energy consumption per unit of GDP, and the gap between the energy consumption ratio of the export trade of the northern province and the GDP energy consumption is over time. Gradually shrinking, and the trade energy consumption ratio is closer to the GDP energy consumption ratio, which means that the energy use efficiency of Hubei Province has gradually increased in recent years, providing strong growth for GDP growth, export structure transformation, environmental quality improvement, etc. stand by. This change reflects the energy structure of Hubei's export products, and is gradually shifting from an energy factor type to a high value-added and lowenergy type.

\section{GRANGER CAUSALITY TEST ANALYSIS}

\section{A. Model setting}

This paper intends to use the vector autoregressive model (VAR) for time series analysis. This model can empirically analyze the impact of total energy consumption on the export trade volume and the possible long-term relationship between Hubei Province from the perspective of time series. Firstly, the ADF stationarity test is carried out on the time series data, and it is judged whether the time series data has stability. Then the Granger causality test is used to analyze whether there is a causal relationship between the export trade volume and the change of energy consumption volume in Hubei Province. By using impulse response function analysis and variance decomposition to measure the dynamic relationship of the stimulus to the joint endogenous variables of each variable in the model.

\section{B. Selection and processing of variables}

This paper selects the time series data from 1988 to 2017 to conduct an empirical analysis between the total energy consumption and export trade volume of Hubei Province. The purpose of empirical analysis is to study the long-term export volume of Hubei Province. influences. The data of total export trade and total energy consumption are selected from the statistical yearbook of Hubei Province, in which the total export trade is processed, and the total export trade is divided by the current consumer price index, and the export price is removed. Total trade, in this article, TX and EX are used to indicate the total export trade and total energy consumption. The data was processed logarithmically, using LTX and LEX to represent the logistic total export trade and total energy consumption.

\section{Analysis of Granger causality}

1) ADF stationarity test: This paper uses Eviews software to test the time series of Hubei's export trade volume and total energy consumption by unit root test.

TABLE I. ADF STATIONARITY TEST

\begin{tabular}{|c|c|c|c|c|c|c|}
\hline \multirow[t]{2}{*}{ Variable } & \multicolumn{3}{|c|}{ Threshold } & \multirow{2}{*}{ ADF } & \multirow{2}{*}{$\mathbf{P}$} & \multirow{2}{*}{ Infer } \\
\hline & $1 \%$ & $5 \%$ & $10 \%$ & & & \\
\hline LEX & -3.689 & -2.972 & -2.625 & -0.687 & 0.8343 & unstationarity \\
\hline DLEX & -3.689 & -2.972 & -2.625 & -3.552 & 0.0138 & stationarity \\
\hline LTX & -3.679 & -2.968 & -2.623 & 0.4568 & 0.9820 & unstationarity \\
\hline DLTX & -3.689 & -2.972 & -2.625 & -5.706 & 0.0001 & stationarity \\
\hline
\end{tabular}

Source: "1988-2017 Hubei Statistical Yearbook"

Note: DLEX represents the first-order difference, DLTX represents the first-order difference, and the root SIC value minimum criterion determines the lag period of each time series data.

It can be seen from the table that the absolute value of the total export value of Hubei Province, that is, the ADF value of LTX is less than the absolute value at the threshold of $1 \%, 5 \%$, and $10 \%$. Therefore, the unit root of the original hypothesis should be accepted as non-stationary sequence.

The absolute value of the total energy consumption of Hubei Province, the ADF value of LEX, is less than the absolute value at the threshold of $1 \%, 5 \%$, and $10 \%$. Therefore, it should be accepted that the null hypothesis has a unit root and is, therefore, a non-stationary sequence.

The existence of unit roots in both LTX and LEX illustrates the instability of the two sequences. The first-order difference values are analyzed for the two-time series variables. DLTX is the total export trade volume after the first-order difference and the absolute value of its $\mathrm{ADF}$ value. It is greater than the absolute value at the $1 \%, 5 \%$, and $10 \%$ threshold levels, so the unit hypothesis is rejected for the null hypothesis, so it is a stationary sequence.

DLEX is the total energy consumption of the first-order difference. The absolute value of its ADF value is greater than the absolute value below the $5 \%$ and $10 \%$ levels, so the unit root of the null hypothesis is rejected, so it is a stationary sequence.

The above shows that DLTX and DLEX are sequences of stationarity, and DLTX and DLEX can pass the stationarity test under first-order difference. 
2) Granger causality test: The stability test has been done in the previous paper. It is known that LTX and LEX are unstable sequences, and DLEX and DLTX are the sequences of stationarity. In order to develop the metrological analysis, two-time series DLEX and DLTX with smoothness are used for calculation.

TABLE II. GRANGER CAUSALITY TEST

\begin{tabular}{|c|c|c|c|}
\hline Granger Causality hypothesis & DF & F & P \\
\hline DLTX does not Granger Cause DLEX & 2 & 0.22957 & 0.7967 \\
\hline DLEX does not Granger Cause DLTX & 2 & 4.42417 & 0.0237 \\
\hline
\end{tabular}

Source: "1988-2017 Hubei Statistical Yearbook"

When the lag period is chosen to be 2, the joint statistic value for DLTX is 0.22957 and the null hypothesis is accepted at the level of probability value of 0.7967 . Even at the $10 \%$ significance level, the original hypothesis cannot be rejected. "DLTX does not Granger Cause DLEX" indicates that the total export trade is not the Granger causality of energy consumption, indicating that the total export trade is not the Granger causality of energy consumption.

The joint statistic of DLEX has a value of 4.42417 and rejects the null hypothesis at a probability value of 0.0237 , rejecting the null hypothesis that "DLEX does not Granger Cause DLTX” at a level of 5\% significance. It is the Granger cause that the total energy consumption in Hubei Province is not the amount of export trade. The test results show that the total energy consumption in Hubei Province is the Granger cause of export trade.

\section{THE TEST OF EMPIRICAL RESULtS}

\section{A. Analysis of impulse response function}

Before performing the pulse function analysis, it is necessary to see whether the VAR model is stable. The unstable VAR model is prone to false regression. The reciprocal modulus of all eigenvalues in the stationary VAR model is less than 1 , which means the reciprocal of the AR eigenvalue. All must fall within the unit circle. First, we need to determine the lag order of the VAR model. According to the optimal lag period criterion, the optimal lag period of AIC is 2, and the unit root test graph with lag period of 2 shows that these reciprocal modes all fall within the unit circle. Therefore, the sturdiness of the VAR model is characterized, so the smooth model can be analyzed by the impulse response function.
Inverse Roots of AR Characteristic Polynomial

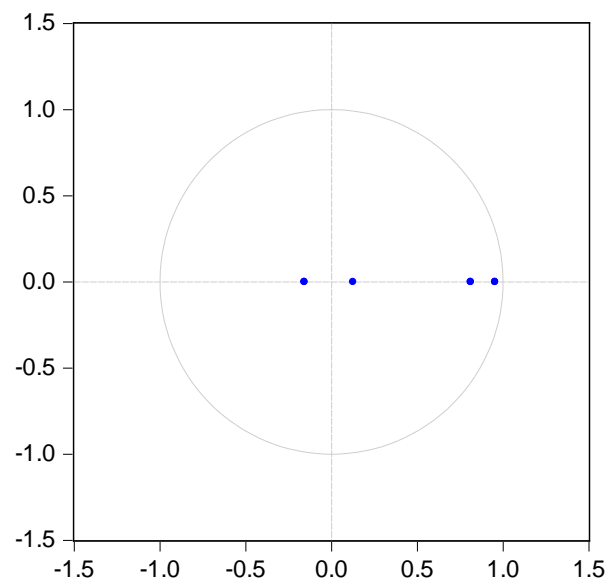

Fig. 1. Unit root test chart

The Fig. 2 explains the test results. The graph in the upper left corner shows the impulse response function of a standard deviation of the energy consumption total LDX. It has a clear upward trend in the first and second periods, and the third phase begins to increase slowly. The total amount of fluctuations in response in the early stage is large, and the fluctuation in the long term is slow. The total energy consumption has a significant positive impact on itself. The upper right corner shows the pulse corresponding function graph of the total export trade LTX by one standard deviation to the total energy consumption LEX, and the lower right corner shows the impact of the total export trade LTX on its own impact.

Response to Cholesky One S.D. Innovations ?2 S.E.
Response of LEX to LEX

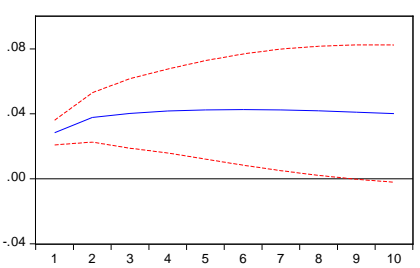

Response of LTX to LEX

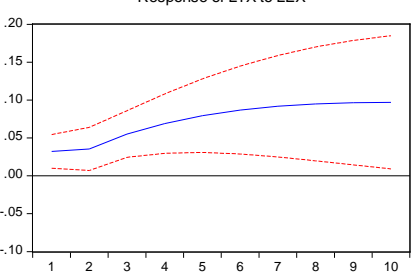

Response of LEX to LTX

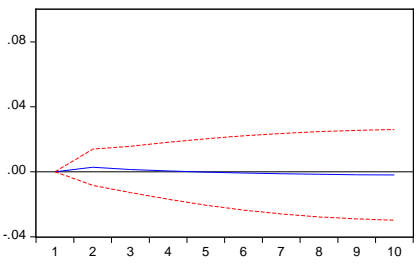

Response of LTX to LTX

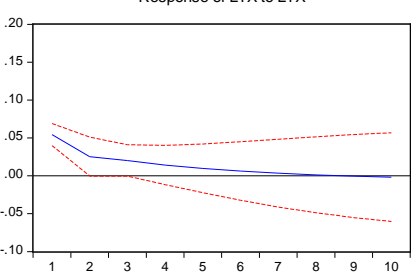

Fig. 2. Impulse response function diagram

The impulse response function analysis shows that the total energy consumption of Hubei Province changes by one standard deviation, which will continue to stimulate the export trade volume of Hubei Province. However, a standard deviation in the volume of export trade has a slight negative stimulus to energy consumption. This shows that the growth of export trade has certain support for total energy consumption. Hubei Province should accelerate the transformation of foreign 
trade growth mode and seek new ways to reduce energy dependence.

\section{B. Variance decomposition}

In this paper, the variance decomposition takes the mutual fluctuation between the two variables to measure the relative importance of the endogenous variable impact. In order to further study the correlation between Hubei's export trade volume and total energy consumption, the results of variance decomposition are shown.

In the figure, Percent LTX Variance due to LEX represents the change in the variance of the total export trade LTX caused by the change in total energy consumption LEX. Percent LTX Variance due to LTX indicates that the total export trade LTX is caused by its own changes. As the number of periods increased, the total export trade volume LTX was gradually reduced by the part explained by its own changes, but the total export trade volume LTX was gradually increased by the part explained by the change in total energy consumption, and reached its peak in the tenth period. Approximately 93\% of the variance in total export trade changes can be explained by changes in total energy consumption.

\section{Variance Decomposition}

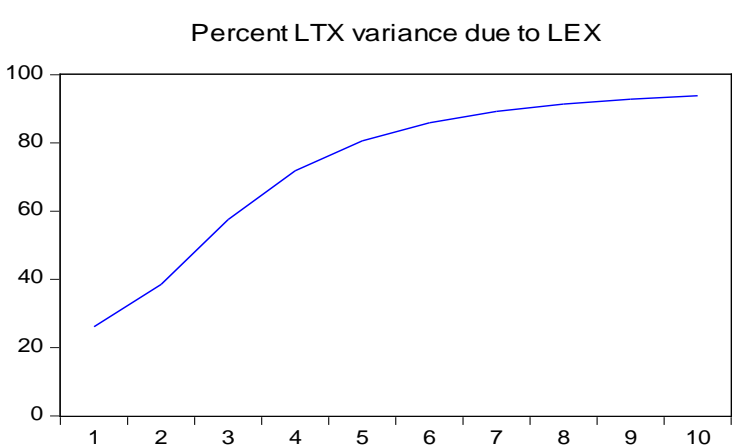

Percent LTX variance due to LTX

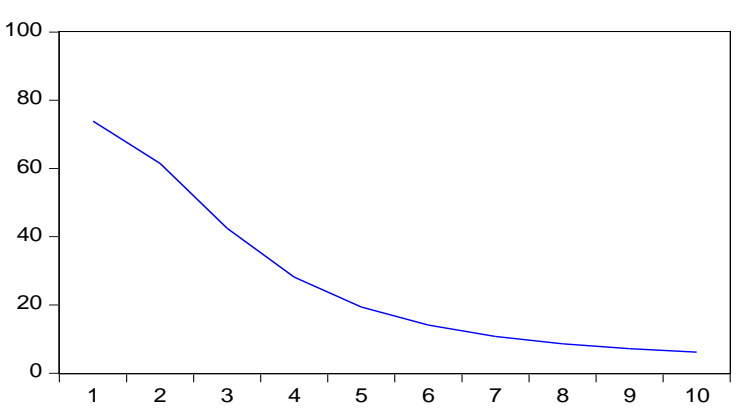

Fig. 3. Variance decomposition diagram

The results of variance decomposition show that over time, the total energy consumption has contributed more and more to the impact of total export trade, but the contribution of total export trade to the total energy consumption has been decreasing. This shows that Hubei needs to accelerate. Steps, formulate policies to reduce the impact of energy consumption on export trade, especially in the case of global energy supply constraints.

\section{CONCLUSION}

In the empirical analysis, this paper selects the time series data of China's export trade volume and total energy consumption from 1988 to 2017. From the perspective of VAR analysis, this paper studies the Granger causality of the total energy consumption in Hubei Province as the export trade volume. The empirical results show that the total energy consumption of Hubei Province will have a positive causal effect on the export trade volume and the increase of total energy consumption has supported the growth of local export trade in history and reality.

Based on this conclusion, this paper has the following recommendations:

At first, under the conditions of constant industrial structure and technological level, increasing energy consumption is an effective way to increase the volume of local export trade.

Secondly, the result of the upgrading and transformation of the industrial structure should be reflected in the local energy consumption structure and the total amount of change, which means that the environmental Kuznets curve inflection point in Hubei has not yet arrived, and energy conservation and emission reduction work has a long way to go.

Thirdly, through technological advancement and industrial structure upgrading, the energy efficiency of export trade will approach the energy efficiency of domestic trade. Therefore, the improvement of trade facilitation level can promote this convergence effect for a long-term.

\section{ACKNOWLEDGMENT}

Acknowledged by Science and Technology Research Project of Hubei Provincial Department of Education: "Research on the Influence Mechanism of Energy Consumption and Export Trade in Hubei Province”.(No. B2019305)

\section{REFERENCES}

[1] Aryel, Hillman, Clarkw, Bullard. Energy The Heckscher - Ohlin Theorem, And U. S. International Trade [J]. The American Economic Review, 1978, (3): 96-106

[2] Kraft, J, Kraft, A. On The Relationship Between Energy And GNP [J]. Energy Economics, 1978, (22): 33-64

[3] T. Owen Carroll, Romir Chatterjee, Vinod Mubayi. Energy Planning Latin America: A Brief Review Of Selected Countries [J]. Latin American Research Review, 1982, (3): 148-172

[4] Jose Goldemberg. Energy Problems In Latin America [J]. Science, 1984, (3): 101-103

[5] Liu Qiang, Zhuang Xin, Jiang Kezhen, Han Wenke. Analysis of energy and carbon emissions in China's export trade [J]. China Industrial Economy, 2008, (8): 46-55. (In Chinese).

[6] Wan Qing, Guo Wenbo, Gong Shengsheng. Time and space pattern of Hubei energy consumption from 2001 to 2009 and its influencing factors [J]. Resources and Development Market, 2011, (10): 920-923. (In Chinese).

[7] Wu Yifan, Qin Zhigang. Empirical analysis of the relationship between Hubei export trade and environmental pollution [J]. China Management Informationization, 2015, (20): 129-131. (In Chinese). 